\title{
Different Effect of Hemodialysis on Function of Human Arterial and Venous Endothelial Cells
}

\author{
Andrzej Bręborowicz \\ Department of Pathophysiology, Poznań University of Medical Sciences, Poznań, Poland
}

Patrycja Sosinska-Zawierucha Ewa Baum Beata Mackowiak Monika Misian

\section{Keywords}

Hemodialysis · Arterial endothelium · Venous endothelium

\begin{abstract}
Background/aims: Hemodialysis causes the systemic inflammatory response, which may affect the function of endothelial cells. Methods: We studied the effect of the serum obtained after a hemodialysis session, compared to serum collected before the start of the treatment, on the gene expression and secretory activity of arterial endothelial cells (AECs) and venous endothelial cells (VECs) in in vitro culture. Results: Serum collected at the end of the hemodialysis session increased expression of the studied genes in VECs, and at the same time decreased their expression in AECs. Secretory activity was increased in VEC: (interleukin-6 [IL-6] +29\%, $p<0.05$, von Willebrand factor $+23 \%, p<0.02$; tissue plasminogen activator [t-PA] $+35 \%, p<0.002$, t-PA/plasminogen activator inhibitor-1 [PAI-1] ratio $+57 \%, p<0.005$ ). In AEC, synthesis of IL- 6 and vascular endothelial growth factor were reduced $(-36 \%, p<0.02,-34 \%, p<0.05$, respectively) and the tPA/PAl- 1 ratio was increased $(+22 \%, p<$ $0.01)$. Conclusions: Hemodialysis induces the inflammatory, procoagulant, and profibrinolytic activity of VEC, whereas suppression of AEC is observed at the same time. Video Journal Club 'Cappuccino with Claudio Ronco' at https:// www.karger.com/Journal/ArticleNews/223997?sponsor=52
\end{abstract}

(c) 2018 S. Karger AG, Basel

\section{KARGER}

(๑) 2018 S. Karger AG, Basel

E-Mail karger@karger.com

www.karger.com/bpu

\section{Introduction}

Hemodialysis is a therapy which helps in the survival of end stage renal failure patients. However, its biocompatibility is relatively low despite various technological innovation in treatment [1]. Contact of blood with the dialysis membrane results in activation of leukocytes, red blood cells, platelets, and the complement system [2]. During a hemodialysis session, concentration of the inflammatory cytokines in blood significantly increases and signs of oxidative stress are present [3].

One can assume that the function of the endothelial cells lining the blood vessels must be affected by hemodialysis. Flow-mediated dilation of the brachial artery is impaired in children and adults treated with hemodialysis, which may reflect deterioration of their endothelial function $[4,5]$. These observations come from studies in which endothelial function was evaluated indirectly, based on the ability of the arteries to dilate. In our previous study, we found that serum obtained at the end of the hemodialysis session stimulated the proliferation of endothelial cells and synthesis of MCP-1 in these cells [6]. Similar observations were presented by Zafeiropoulou et al. [7]. These effects could be due to the removal of uremic toxins during dialysis which makes serum less harmful to the endothelial cells but at the same time dialysis-induced inflammatory reaction 
may stimulate these cells $[6,7]$. All studies were performed on human umbilical venous endothelial cells (VECs). There are no data describing whether the changes in serum composition during hemodialysis affect the function of the arterial endothelial cells (AECs) in the same way. We present results from a study in which we compared the effect of the serum samples collected before and at the end of the hemodialysis session on human umbilical VECs and AECs in conditions of the in vitro culture.

\section{Material and Methods}

The study was approved by the Ethical Committee at Poznan University of Medicine. All patients participating in the study gave their informed consent. Serum samples were collected from 22 end stage renal failure patients treated with hemodialysis, before the start of the hemodialysis session and after $4 \mathrm{~h}$ of that treatment. We compared the changes in the properties of serum after $4 \mathrm{~h}$ of the hemodialysis therapy, as compared to the predialysis serum. The mean age of the patients was $53.4 \pm 7.2$ years, and the duration of the renal replacement therapy was $41 \pm 25$ months and GFR $7.9 \pm 4.1$. Diabetics or patients with chronic inflammatory systemic diseases were excluded from the study. In all patients, standard hemodialysis treatment was applied with a polysulfone dialyzer (Fresenius, Bad Homburg, Germany). Collected serum samples were stored at $-86^{\circ} \mathrm{C}$ until they were tested on human AECs and human umbilical VECs. AECs and VECs were obtained from Life Technologies Corporation (Carlsbad, CA, USA). Cell cultures were established in M200 medium supplemented with $2 \%$ fetal bovine serum, hydrocortisone $1 \mu \mathrm{g} / \mathrm{mL}$, heparin $10 \mu \mathrm{g} / \mathrm{mL}$, human epidermal growth factor $10 \mathrm{ng} / \mathrm{mL}$, and basic fibroblast growth factor $3 \mathrm{ng} /$ $\mathrm{mL}$.

\section{Evaluation of Cells' Secretory Activity}

Experiments were performed on AEC and VEC monolayers. Cells were exposed to the studied serum samples added to the culture medium (20\%) and incubated for $24 \mathrm{~h}$. Afterwards, the medium was removed and replaced with serum free medium for evaluation during the following $24 \mathrm{~h}$ of the cells secretory activity. At the end of the incubation supernatant from the wells was collected for measurement of the studied molecules with commercially available ELISA kits:

- Interleukin-6 (IL-6)

- Von Willebrand factor (vWF)

- Vascular endothelial growth factor (VEGF)

- Tissue plasminogen activator ( $\mathrm{t}-\mathrm{PA})$

- Plasminogen activator inhibitor-1 (PAI-1)

Secretory activity of the cells was expressed per amount of the cellular protein.

\section{Gene Expression Analysis}

Changes in gene expression in AEC and UVEC were examined using the real-time PCR method. Reverse transcription of RNA was performed using the iScript cDNA Synthesis Kit (Bio-
Rad, Hercules, USA). Relative levels of mRNA of 7 genes of interest - interleukin-6 (IL-6), vWF, vascular cell adhesion protein 1 [VCAM], VEGF, endothelin 1 (EDN1), tPA, urokinase plasminogen activator ( $u P A)$ - were analyzed. Sequence-specific primers for the amplification of each gene were designed using PrimerBLAST [8].

\section{Statistical Analysis}

Results are presented as mean \pm SEM. Statistical analysis was performed with the Wilcoxon test. A $p$ value less than 0.05 was considered statistically significant.

\section{Results}

We observed differences, in pattern and magnitude, between the effects of the serum collected from patients before the hemodialysis session and at the end of the treatment on the function of AEC and VEC. In VEC, in most cases serum collected at the end of the dialysis had increased expression of genes, as compared to the effect of the serum sample obtained before the start of the session, whereas opposite effects were observed for AEC (Fig. 1). In VEC, increased expression of the following genes was observed: IL-6 $(+22 \%, p<0.01)$, VCAM $(+112 \%, p<0.01), \mathrm{EDN} 1(+159 \%, p<0.01)$, $\mathrm{vWF}(+68 \%$, $p<0.01)$, t-PA $(+162 \%, p<0.01)$, and $u P A(+36 \%, p<$ $0.01)$. In AEC, the expression of no gene was increased during hemodialysis, conversely the expression of some was decreased: IL-6 $(-69 \%, p<0.05)$, VEGF $(-37 \%, p<$ $0.01)$, VCAM $(-87 \%, p<0.01)$, EDN1 $(-49 \%, p<0.01)$, vWF $(-64 \%, p<0.01)$, t-PA $(-21 \%, p<0.01)$, and uPA $(-88 \%, p<0.01)$.

Changes in genes expression were partially reflected by the modification of the secretory pattern of AEC and VEC. Synthesis of IL-6 was lower in AEC (-36\%, $p<$ $0.02)$ and higher in VEC $(+26 \%, p<0.05$; Fig. 2$)$. Synthesis of VEGF was reduced in AEC $(-34 \%, p<0.05)$ and unchanged in VEC. In VEC, synthesis of vWF was increased by $23 \%, p<0.02$. We did not observe significant changes in the secretion of t-PA or PAI- 1 in AEC. But in VEC, after exposure to serum collected at the end of the hemodialysis session, secretion of t-PA was increased by $35 \%, p<0.002$ (Fig. 3). Despite the fact that secretion of PAI-1 was not significantly reduced after exposure of AEC or VEC to serum samples obtained at the end of the dialysis, the ratio of tPA/PAI-1 secretion, reflecting cellular net fibrinolytic activity, was increased in both types of cells by $22 \%, p<0.01$ and by $57 \%, p<$ 0.005 , respectively. 
Fig. 1. Expression of genes for the selected proteins in arterial endothelial cells (AEC, white bar) and venous endothelial cells (VEC, black bar) after their exposure to serum samples collected at the end of the hemodialysis session, expressed as a relative change versus expression of these genes in cells exposed to serum collected before start of the hemodialysis. ${ }^{*} p<0.05 ;{ }^{* *} p<$ 0.01. IL-6, interleukin-6; VEGF, vascular endothelial growth factor; VCAM, vascular cell adhesion protein; EDN1, endothelin 1; vWF, von Willebrand factor; t-PA, tissue plasminogen activator; uPA, urokinase plasminogen activator.
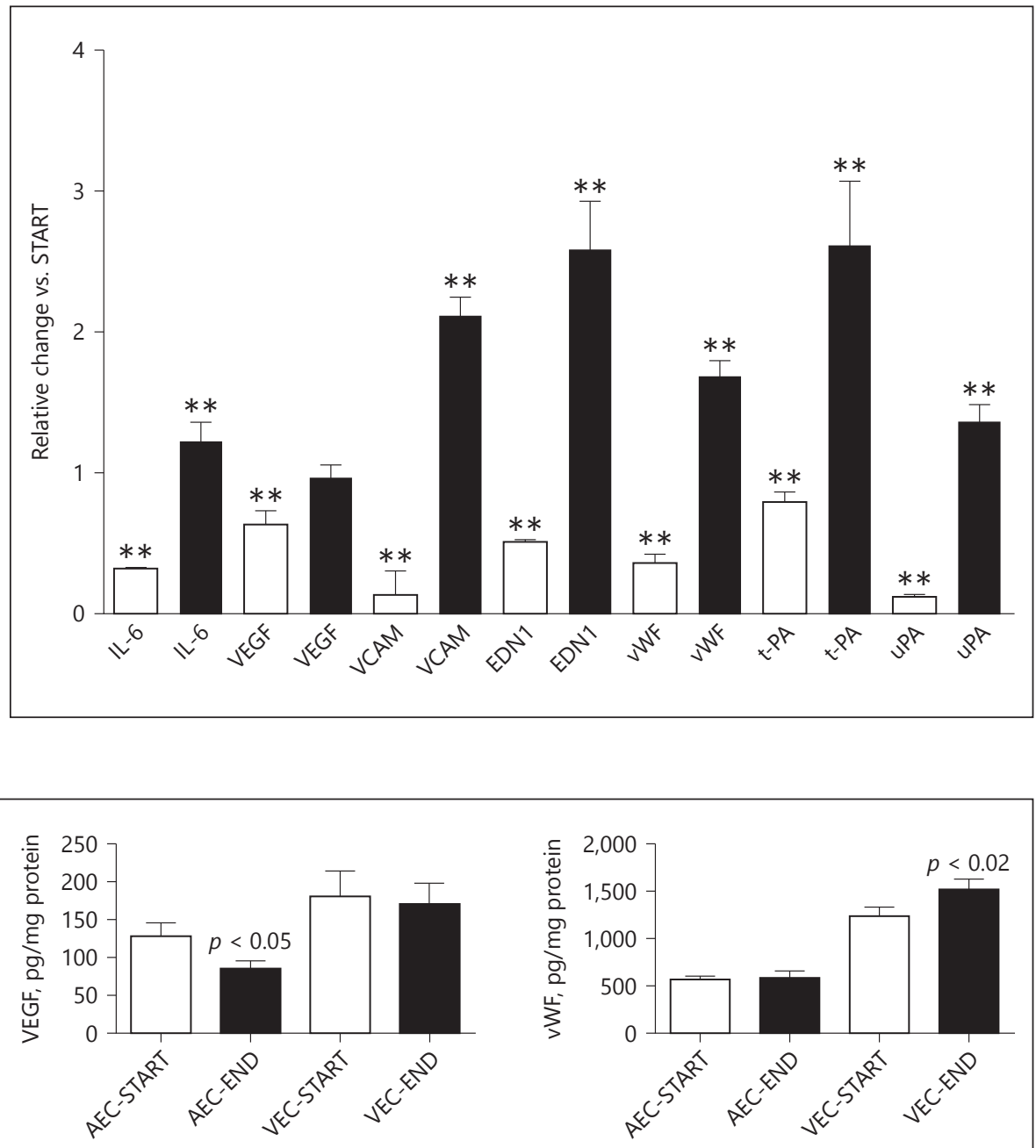

Fig. 2. Synthesis of IL-6, VEGF, and vWF in AEC and VEC after exposure to serum collected before start of hemodialysis (START) and serum collected at the end of the dialysis session (END). Statistical significance, between START and END for each type of cells is shown. IL-6, interleukin-6; AEC, arterial endothelial cell; VEC, venous endothelial cell; VEGF, vascular endothelial growth factor; vWF, von willebrand factor.

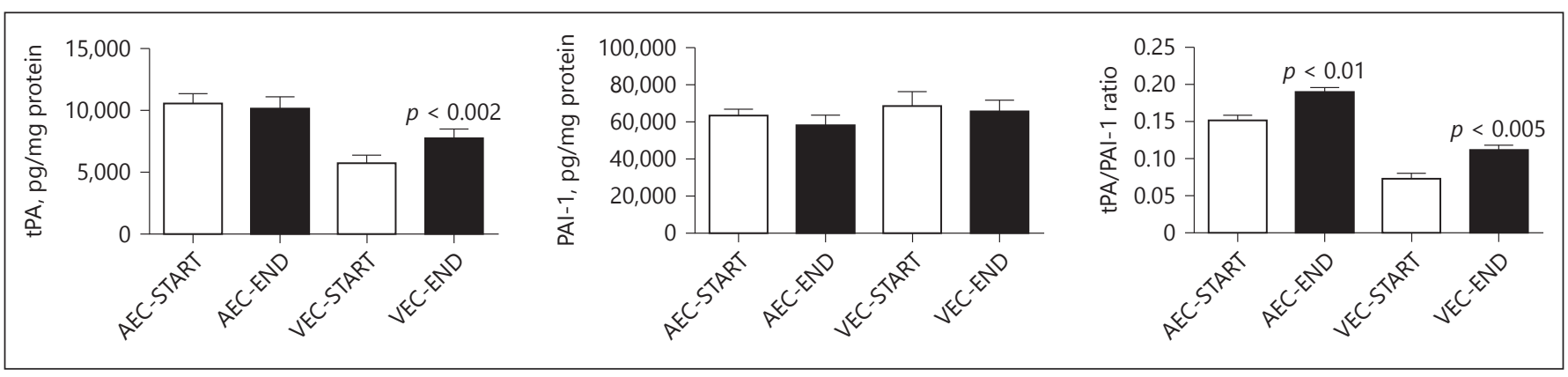

Fig. 3. Synthesis of t-PA, PAI-1 and ratio of secreted t-PA/PAI-1 in AEC and VEC after exposure to serum collected before start of hemodialysis (START) and serum collected at the end of the dialysis session (END). Statistical significance, between START and
END for each type of cells is shown. t-PA, tissue plasminogen activator; AEC, arterial endothelial cell; VEC, venous endothelial cell; PAI-1, plasminogen activator inhibitor-1. 


\section{Discussion}

Contact of blood with the dialysis membrane results in the induction of intravascular inflammation. The character and intensity of that effect depends on the type of dialysis membrane used during treatment [9]. In our study, all patients were dialyzed with the polysulfone dialyzer and therefore the effect of the dialysis membrane on the blood was identical in all of them. During hemodialysis, VECs are activated by the hemodynamic shear stress induced by the pulsatile blood flow [10]. Our study was static because cells were not exposed to flowing blood. The results of our study show how the dialysis induced changes in the composition of the serum affect the function of endothelial cells. Experiments were performed on the endothelial monolayers in in vitro culture, what is an accepted method for testing modulating effect of various compounds on the functional status of cells [11]. In such experimental models, secretory activity of cells can be easily evaluated, but on the other hand we cannot study effects of interaction with other cells in in vivo environment. An interesting and new observation was the totally different effect of serum on AECs and VECs. In VECs, we found increased expression of the proinflammatory, procoagulant, and profibrinolytic genes and increased expression of the gene regulating synthesis of EDN1 (Fig. 1). These changes partially translated into the secretory pattern of these cells as reflected by the increased secretion of IL-6 and vWF (Fig. 2) and t-PA (Fig. 3). In AECs, we observed decreased expression of all studied genes (Fig. 1). Different reactions in AECs and VECs after exposure to studied serum samples may be due to significant differences in morphology and functional properties of these cells [12].

One of the consequences of hemodialysis is the activation of blood coagulation during treatment and that effect is complex including changes of the platelet function as well as increased release of $\mathrm{VWF}$, which may reflect the activation of endothelial cells [13]. Our results show that the activated VECs are the main site of VVW release during hemodialysis. These cells also had stronger expression of genes regulating the synthesis of t-PA and secretion of that molecule was increased in the presence of post-hemodialysis serum, which translated into the stronger net fibrinolytic activity of these cells (Fig. 3). Increased blood level of t-PA was observed in patients at the end of the dialysis session and our data confirm that VECs are the site of its release [14]. Our results show that both AECs and VECs demonstrate increased fibrinolytic activity at the end of dialysis, as reflected by the increased t-PA/PAI-
1 ratio (Fig. 3), which may partially counteract the procoagulant effect of VECs.

We also found increased expression of gene regulating EDN1 synthesis in VECs after their exposure to the posthemodialysis serum (Fig. 1). A significant rise of the EDN1 blood level was observed in patients at the end of the hemodialysis session [15]. Increased release of EDN1 from the endothelial cells may predispose patients to episodes of intradialytic hypertension [16] and in the longer term may accelerate atherosclerosis in the arterial system [17].

The presented results demonstrate significant dysfunction of VECs caused by the process of hemodialysis. These findings are opposite to data presented by Silva et al. [18], who reported that the process of hemodialysis reduced oxidative stress and improved venous endothelial function as reflected by the improved endotheliumdependent venodilation test. In another clinical studies, hemodialysis-induced oxidative stress and endothelial dysfunction were described $[19,20]$. One can assume that hemodialysis-induced imbalance between the endothelial procoagulant and profibrinolytic activities may predispose to thromboembolic events in that group of patients [21]. End stage renal failure patients have higher risk of deep vein thrombosis than patients with preserved renal function [22]. Therefore, in clinical practice, use of drugs reducing inflammatory and thrombotic reactions in the VECs may be beneficial.

An important finding in that study is the difference in the effect of post-hemodialysis serum on AECs and VECs. Recently, Shrestha et al. [23] reported that VECs are more susceptible to the oxidative stress than AECs. These data support the opinion that oxidative stress plays a major role in the dysfunction of endothelial cells in patients treated with hemodialysis [24]. In our previous study, we demonstrated that serum collected from patients at the end of hemodialysis session induces oxidative stress in VECs [6]. Therefore, the introduction of antioxidant treatment in end stage renal patients maintained on renal replacement therapy seems to be an adequate response [24]. Further studies are required to explain why strong suppression of AECs, as reflected by reduced gene expression and secretory activity, was found in the present experiments and what may be the clinical consequences of this effect. Additionally we need to find out how long the hemodialysis induced dysfunction of endothelial cells lasts. The results from such research may be important from the clinical point of view and may help in finding how to reduce the cardiovascular risk in patients with the end stage renal failure. 


\section{Acknowledgment}

The research was supported by the following grants from the National Science Center Poland: UMO-2013/11/B/NZ4/04740; IUVENTUS Plus 0733/IP1/2016/74.

\section{Disclosure Statement}

The authors do not disclose any conflict of interest.

\section{References}

1 Uda S, Mizobuchi M, Akizawa T: Biocompatible characteristics of high-performance membranes. Contrib Nephrol 2011;173:2329.

2 Kokubo K, Kurihara Y, Kobayashi K, Tsukao $\mathrm{H}$, Kobayashi H: Evaluation of the biocompatibility of dialysis membranes. Blood Purif 2015;40:293-297.

3 Liakopoulos V, Roumeliotis S, Gorny X, Dounousi E, Mertens PR: Oxidative stress in hemodialysis patients: a review of the literature. Oxid Med Cell Longev 2017;2017:3081856.

4 Lilien MR, Koomans HA, Schröder CH: Hemodialysis acutely impairs endothelial function in children. Pediatr Nephrol 2005;20: 200-204.

5 Migliacci R, Falcinelli F, Imperiali P, Floridi A, Nenci GG, Gresele P: Endothelial dysfunction in patients with kidney failure and vascular risk factors: acute effects of hemodialysis. Ital Heart J 2004;5:371-377.

6 Oleśkowska-Florek W, Połubinska A, Baum E, Matecka M, Pyda M, Pawlaczyk K, Bręborowicz A: Hemodialysis-induced changes in the blood composition affect function of the endothelium. Hemodial Int 2014 18:650-656.

7 Zafeiropoulou K, Bita T, Polykratis A, Karabina S, Vlachojannis J, Katsoris P: Hemodialysis removes uremic toxins that alter the biological actions of endothelial cells. PLoS One 2012;7:e30975.

8 Ye J, Coulouris G, Zaretskaya I, Cutcutache I, Rozen S, Madden TL: Primer-BLAST: a tool to design target-specific primers for polymerase chain reaction. BMC Bioinformatics 2012;13:134.

9 Hoffmann U, Fischereder M, Marx M, Schweda F, Lang B, Straub RH, Krämer BK: Induc- tion of cytokines and adhesion molecules in stable hemodialysis patients: is there an effect of membrane material? Am J Nephrol 2003; 23:442-447.

10 Franzoni M, Cattaneo I, Longaretti L, Figliuzzi M, Ene-Iordache B, Remuzzi A: Endothelial cell activation by hemodynamic shear stress derived from arteriovenous fistula for hemodialysis access. Am J Physiol Heart Circ Physiol 2016;310:H49-H59.

11 Cao Y, Gong Y, Liu L, Zhou Y, Fang X, Zhang C, Li Y, Li J: The use of human umbilical vein endothelial cells (HUVECs) as an in vitro model to assess the toxicity of nanoparticles to endothelium: a review. J Appl Toxicol 2017;37:1359-1369.

12 Wagner WH, Henderson RM, Hicks HE Banes AJ, Johnson G Jr: Differences in morphology, growth rate, and protein synthesis between cultured arterial and venous endothelial cells. J Vasc Surg 1988;8:509-519.

13 Schoorl M, Schoorl M, Nubé MJ, Bartels PC: Platelet depletion, platelet activation and coagulation during treatment with hemodialysis. Scand J Clin Lab Invest 2011;71:240-247.

14 Speiser W, Wojta J, Korninger C, Kirchheimer JC, Zazgornik J, Binder BR: Enhanced fibrinolysis caused by tissue plasminogen activator release in hemodialysis. Kidney Int 1987;32:280-283.

15 Liakopoulos V, Wurth P, Mertens PR, Eleftheriadis T, Kourti P, Voliotis G, Heintz B, Koukoulis GN, Stefanidis I: Endothelin-1 plasma levels in hemodialysis treatment - the influence of type 2 diabetes. Ren Fail 2005;27: 515-522.

16 Teng J, Tian J, Lv WL, Zhang XY, Zou JZ, Fang Y, Yu J, Shen B, Liu ZH, Ding XQ: Inappropriately elevated endothelin-1 plays a role in the pathogenesis of intradialytic hypertension. Hemodial Int 2015;19:279-286.

17 Liu H, Peng Y, Liu F, Liu Y, Ouyang L, Xiao W, Cheng M, Chen X, Gao L: Correlation between endothelin-1 and atherosclerosis in chronic hemodialysis patients. J Nephrol 2010;23:593-602.

18 Silva AM, Signori LU, Plentz RD, Moreno H $\mathrm{Jr}$, Barros E, Belló-Klein A, Schaan BD, Irigoyen MC: Hemodialysis improves endothelial venous function in end-stage renal disease. Braz J Med Biol Res 2008;41:482-488.

19 Miyazaki H, Matsuoka H, Itabe H, Usui M, Ueda S, Okuda S, Imaizumi T: Hemodialysis impairs endothelial function via oxidative stress: effects of vitamin E-coated dialyzer. Circulation 2000;101:1002-1006.

20 Errakonda PR, Paladugu R, Bitla AR, Musturu SM, Lakshman J, Pemmaraju SR, Vishnubhotla S: Effect of a single hemodialysis session on endothelial dysfunction. J Nephrol 2011; 24:83-90.

21 Casserly LF, Dember LM: Thrombosis in endstage renal disease. Semin Dial 2003;16:245256.

22 Lu HY, Liao KM: Increased risk of deep vein thrombosis in end-stage renal disease patients. BMC Nephrol 2018;19:204.

23 Shrestha B, Prasai PK, Kaskas AM, Khanna A, Letchuman V, Letchuman S, Alexander JS, Orr AW, Woolard MD, Pattillo CB: Differential arterial and venous endothelial redox responses to oxidative stress. Microcirculation 2018:25:e12486.

24 Del Vecchio L, Locatelli F, Carini M: What we know about oxidative stress in patients with chronic kidney disease on dialysis - clinical effects, potential treatment, and prevention. Semin Dial 2011;24:56-64. 